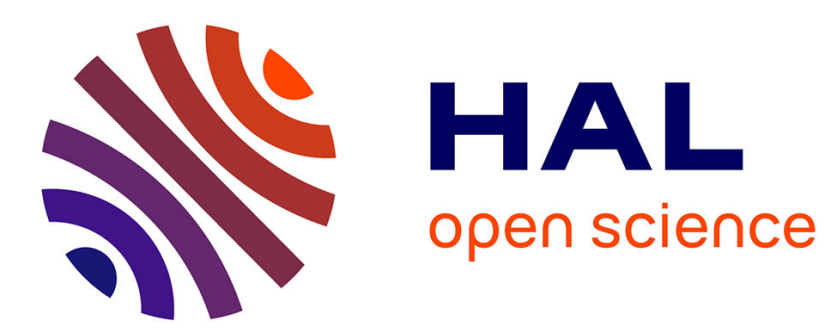

\title{
Influence of kinetic and electrostatic properties of interface states on the efficiency of a MIS tunnel solar cell
}

\author{
G. Pananakakis, G. Kamarinos, P. Viktorovitch
}

\section{- To cite this version:}

G. Pananakakis, G. Kamarinos, P. Viktorovitch. Influence of kinetic and electrostatic properties of interface states on the efficiency of a MIS tunnel solar cell. Revue de Physique Appliquée, 1979, 14 (5), pp.639-647. 10.1051/rphysap:01979001405063900 . jpa-00244642

HAL Id: jpa-00244642

https://hal.science/jpa-00244642

Submitted on 1 Jan 1979

HAL is a multi-disciplinary open access archive for the deposit and dissemination of scientific research documents, whether they are published or not. The documents may come from teaching and research institutions in France or abroad, or from public or private research centers.
L'archive ouverte pluridisciplinaire $\mathbf{H A L}$, est destinée au dépôt et à la diffusion de documents scientifiques de niveau recherche, publiés ou non, émanant des établissements d'enseignement et de recherche français ou étrangers, des laboratoires publics ou privés. 


\title{
Influence of kinetic and electrostatic properties of interface states on the efficiency of a MIS tunnel solar cell
}

\author{
G. Pananakakis, G. Kamarinos and P. Viktorovitch \\ " Physique des Composants à Semiconducteurs », ERA C.N.R.S. nº 659, ENSER \\ 23, avenue des Martyrs, 38031 Grenoble-Cedex, France \\ (Reçu le 10 octobre 1978, révisé le 1 er février 1979, accepté le 7 février 1979)
}

\begin{abstract}
Résumé. - Nous établissons et résolvons les équations de transport complètes décrivant le fonctionnement d'une cellule solaire MIS tunnel. Nous tenons compte de l'influence aussi bien électrostatique que cinétique des états situés à l'interface semiconducteur-isolant. Ces états de type accepteur ou donateur sont ainsi considérés en interaction avec les trois réservoirs de porteurs libres : bande de conduction du métal, bandes de conduction et de valence du semiconducteur. Outre ce cas général, les états peuvent avoir une interaction importante seulement avec deux parmi les trois réservoirs de porteurs. Ils peuvent alors constituer selon le cas des centres recombinants ou des relais facilitant le passage de courants additionnels entre le métal et l'une des bandes permises du semiconducteur. Notre étude montre que pour un semiconducteur de type $\mathbf{n}$ les états d'interface du type donateur peuvent détériorer le rendement photovoltaïque de la cellule surtout si leur action électrostatique défavorable est accompagnée d'effets cinétiques. Au contraire, des états accepteurs peuvent améliorer notablement le rendement photovoltaïque, grâce essentiellement à leur action électrostatique. De manière générale nous montrons que l'effet de suppression de courant est principalement dû à l'action électrostatique des états d'interface tandis que les effets cinétiques affectent seulement la tension de circuit ouvert.
\end{abstract}

\begin{abstract}
We establish and resolve the complete transport equations governing the working of a MIS tunnel solar cell. We take into account both electrostatic and kinetic actions of acceptor-like or donor-like interface states. Our study shows that for a n-type semiconductor donor-like interface states deteriorate the photovoltaic efficiency of the cell, especially when their unfavourable electrostatic action is assisted by a notable kinetic one. Acceptor-like interface states can, on the contrary, lead to an important improvement of the photovoltaic yield. In a general manner, we show that the current suppression effect is essentially due to an electrostatic action of interface states. Besides we point out that recombination effects can only affect the open-circuit voltage.
\end{abstract}

1. Introduction. - Recent experimental works [1, 2, 3] confirming theoretical but qualitative approaches $[4,5]$ have given evidence of the improvement of the photovoltaic yield of the Schottky diode by adjoining an insulating layer between the metal and the semiconductor.

In several previous papers we have described the working of a MIS tunnel solar cell. Particularly we have given in details the influence of interface states when they act only electrostatically. This case occurs if the surface states communicate with one of the three reservoirs of free carriers : conduction and valence band of the semiconductor and conduction band of the metal $[6,7,8]$.

Nevertheless the above model is too simple to describe the actual mechanisms of working of the MIS structure ; especially it does not take into account an eventual transport of carriers through interface states.
In this paper we write and resolve numerically the complete equations governing the working of a MIS tunnel diode under illumination in the presence of interface states connected with the three carrier reservoirs, that is both their electrostatic and kinetic action are taken into account. In our calculations we consider single energy level interface states. In fact in real MIS devices the interface states are continuously distributed in energy range $[9,10,11]$. Nevertheless, we think that the action of these states can be theoretically described by moving single level states in energy range and by varying their density. This approach leads to a good understanding of the working of the MIS structure with regard to the energy level and density of the interface states.

2. Basic equations. - Let us write first the carriers fluxes through the surface states (Fig. 1a).

We assume that the interface states of density $N_{t}$ 
occupy a single energy level $E_{\mathrm{t}}$; they are also independent of one another $[12,13,14,15]$ :

$$
\begin{aligned}
& j_{\mathrm{nt}}=C_{\mathrm{n}} N_{\mathrm{t}}\left((1-f) n_{\mathrm{s}}-f n_{1}\right) \\
& j_{\mathrm{pt}}=C_{\mathrm{p}} N_{\mathrm{t}}\left(f p_{\mathrm{s}}-(1-f) p_{1}\right) \\
& j_{\mathrm{mt}}=\frac{N_{\mathrm{t}}}{\tau}\left(f_{\mathrm{m}}-f\right)
\end{aligned}
$$

where :

$j_{\mathrm{nt}}$ is the net flux of electrons from the conduction band of the semiconductor into the interface states; $j_{\mathrm{pt}}$ is the net flux of holes from the valence band of the semiconductor into the interface states; finally $j_{\mathrm{mt}}$ is the tunnel flux of electrons from the metal into the states;

in the appendix we deduce the above expression of $j_{\mathrm{mt}}$ by a simple method based on a chemical-thermodynamical formalism;

$$
\begin{aligned}
n_{1} & =N_{\mathrm{c}} \exp \left(\frac{E_{\mathrm{t}}-E_{\mathrm{c}}}{k T}\right) \\
& =N_{\mathrm{v}} \exp \left(\frac{E_{\mathrm{v}}-E_{\mathrm{t}}}{k T}\right) \\
p_{1} & =\tau_{0} \exp \left(\chi^{1 / 2} \delta\right) \\
\tau & =\left(1+\exp \frac{E_{\mathrm{t}}-E_{\mathrm{Fm}}}{k T}\right)^{-1} .
\end{aligned}
$$

The occupation rate $f$ of the states can be calculated by expressing that, in steady state conditions, the total flux of electrons into the states is null :

$$
N_{\mathrm{t}} \frac{\partial f}{\partial t}=j_{\mathrm{nt}}-j_{\mathrm{pt}}+j_{\mathrm{mt}}=0
$$

from (4) and (1), (2), (3), we deduce :

$$
\begin{array}{r}
f=\frac{C_{\mathrm{p}} p_{1}+C_{\mathrm{n}} n_{\mathrm{s}}+\frac{f_{\mathrm{m}}}{\tau}}{C_{\mathrm{n}}\left(n_{\mathrm{s}}+n_{1}\right)+\frac{1}{\tau}+C_{\mathrm{p}}\left(p_{\mathrm{s}}+p_{1}\right)}= \\
=\frac{C_{\mathrm{p}} p_{1}+C_{\mathrm{n}} n_{\mathrm{s}}+\frac{f_{\mathrm{m}}}{\tau}}{D}
\end{array}
$$

where :

$$
D=C_{\mathrm{n}}\left(n_{\mathrm{s}}+n_{1}\right)+C_{\mathrm{p}}\left(p_{\mathrm{s}}+p_{1}\right)+\frac{1}{\tau} .
$$

Using (5), (1), (2), $j_{\mathrm{nt}}$ and $j_{\mathrm{pt}}$ can be rewritten :

$$
\begin{aligned}
& j_{\mathrm{nt}}=J_{\mathrm{R}}-J_{\mathrm{nt}}=S \delta n-J_{\mathrm{nt}} \\
& j_{\mathrm{pt}}=J_{\mathrm{R}}-J_{\mathrm{pt}}=S \delta p-J_{\mathrm{pt}} \quad(\delta n=\delta p) ;
\end{aligned}
$$

$J_{\mathrm{R}}$ is the recombination current with :

$$
S=\frac{C_{\mathrm{n}} C_{\mathrm{p}} N_{\mathrm{t}}\left(n_{0}+p_{0}+\delta n\right)}{D}
$$

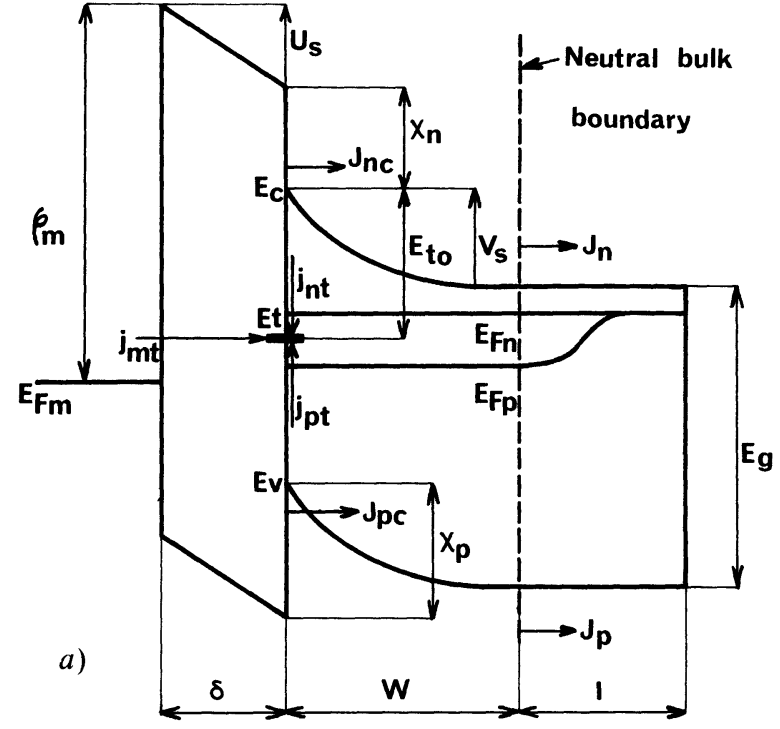

b)

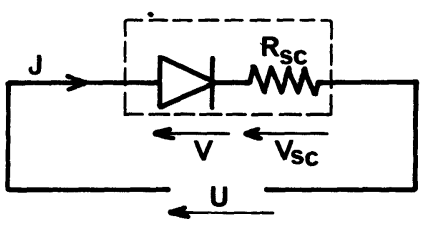

Fig. 1. - a) Energy band diagram and different fluxes of the MIS tunnel diode (n-type semiconductor). $b$ ) Schematic electrical representation of the MIS tunnel structure.

(which may be regarded as a recombination velocity at the surface);

$$
\begin{aligned}
J_{\mathrm{nt}}= & \left(\frac{C_{\mathrm{n}} N_{\mathrm{t}}}{\tau}\left(1-f_{\mathrm{m}}\right) \frac{1}{D}\right) n_{0} \exp \left(q \frac{V_{\mathrm{s}_{\mathrm{o}}}}{k T}\right) \times \\
& \quad \times \exp \left(-q \frac{\delta U_{\mathrm{s}}}{k T}\right)\left(1-\frac{n}{n_{\mathrm{o}}} \exp \frac{q V}{k T}\right)=v_{\mathrm{n}} \cdot N \\
J_{\mathrm{pt}}= & \left(\frac{C_{\mathrm{p}} N_{\mathrm{t}}}{\tau} f_{\mathrm{m}} \frac{1}{D}\right) p_{0} \exp \left(-q \frac{V_{\mathrm{s}_{0}}}{k T}\right) \times \\
& \times \exp \left(q \frac{\delta U_{\mathrm{s}}}{k T}\right)\left(1-\frac{p}{p_{0}} \exp \left(-\frac{q V}{k T}\right)\right)=v_{\mathrm{p}} \cdot P
\end{aligned}
$$

where :

$$
\begin{aligned}
N=n_{0} \exp \left(\frac{q V_{\mathrm{s}_{0}}}{k T}\right) \exp ( & \left.-\frac{q \delta U_{\mathrm{s}}}{k T}\right) \times \\
& \times\left(1-\frac{n}{n_{0}} \exp \frac{q V}{k T}\right) \\
P=p_{0} \exp \left(-\frac{q V_{\mathrm{s}_{\mathrm{o}}}}{k T}\right) \exp \frac{q \delta U_{\mathrm{s}}}{k T} \times & \\
\times & \left(1-\frac{p}{p_{0}} \exp \left(-\frac{q V}{k T}\right)\right) ;
\end{aligned}
$$


the variation of the voltage drop across the junction is :

$$
\begin{aligned}
V=\delta U_{\mathrm{s}}+\delta V_{\mathrm{s}}= & \left(U_{\mathrm{s}}-U_{\mathrm{s}_{0}}\right)+ \\
& +\left(V_{\mathrm{s}}-V_{\mathrm{s}_{0}}\right)=U_{\mathrm{s}}+V_{\mathrm{s}}+\frac{\varphi_{\mathrm{ms}}}{q} ;
\end{aligned}
$$

$J_{\mathrm{nt}}$ and $J_{\mathrm{pt}}$ are electron and hole fluxes from the metal to the semiconductor, through the interface states.

The voltage drop across the insulator is generally given by :

$$
U_{\mathrm{s}}=-\frac{\delta}{\varepsilon_{\mathrm{i}}}\left(Q_{\mathrm{sc}}+Q_{\mathrm{ss}}\right)
$$

where :

$$
\begin{aligned}
Q_{\mathrm{sc}}= & -\left(\operatorname{sign} V_{\mathrm{s}}\right)\left(2 \varepsilon_{\mathrm{s}} k T\right)^{1 / 2}\left(n\left(\exp \frac{q V_{\mathrm{s}}}{k T}-1\right)+\right. \\
& \left.+p\left(\exp \frac{-q V_{\mathrm{s}}}{k T}-1\right)-\left(N_{\mathrm{D}}-N_{\mathrm{A}}\right) \frac{q}{k T} V_{\mathrm{s}}\right)^{1 / 2} ;
\end{aligned}
$$

$Q_{\mathrm{ss}}=-q N_{\mathrm{t}} f$ for acceptor-like surface states

$Q_{\mathrm{ss}}=q N_{\mathrm{t}}(1-f)$ for donor-like surface states.

We can now express the total fluxes crossing the MIS structure; for simplicity we consider a n-type semiconductor. We express first the continuity of electron and hole flows at the neutral bulk boundary of the semiconductor (see Fig. 1a) :

$$
\begin{aligned}
& \begin{aligned}
& J_{\mathrm{n}}=-n\left|\mu_{\mathrm{n}}\right| E-D_{\mathrm{n}} \frac{\partial n}{\partial x}= \\
&=\varphi_{0}(1-\exp (-\alpha W))+J_{\mathrm{nc}}^{*} \\
& J_{\mathrm{p}}=p \mu_{\mathrm{p}} E-D_{\mathrm{p}} \frac{\partial p}{\partial x}=\varphi_{0}(1-\exp (-\alpha W))+J_{\mathrm{pc}}^{*}
\end{aligned}
\end{aligned}
$$

where the total collection fluxes $J_{\mathrm{nc}}^{*}$ and $J_{\mathrm{pc}}^{*}$ are given by (see eqs. (6) to (9)) :

$$
\begin{aligned}
& J_{\mathrm{nc}}^{*}=J_{\mathrm{nc}}-j_{\mathrm{nt}}=J_{\mathrm{nc}}+J_{\mathrm{nt}}-J_{\mathrm{R}} \\
& J_{\mathrm{pc}}^{*}=J_{\mathrm{pc}}-j_{\mathrm{pt}}=J_{\mathrm{pc}}+J_{\mathrm{pt}}-J_{\mathrm{R}} ;
\end{aligned}
$$

$J_{\mathrm{nc}}$ and $J_{\mathrm{pc}}$ are the direct collection fluxes given by :

$$
\begin{aligned}
& J_{\mathrm{nc}}=v_{\mathrm{cn}} \cdot \exp \left(-\chi^{1 / 2} \delta\right) \cdot N \\
& J_{\mathrm{pc}}=v_{\mathrm{cp}} \cdot \exp \left(-\chi^{1 / 2} \delta\right) \cdot P .
\end{aligned}
$$

An elegant and simple method for deducing this current is given in appendix.

The electric field at the neutral bulk boundary can be calculated by integrating the total current $q\left(J_{\mathrm{p}}-J_{\mathrm{n}}\right)$ over the length 1 of the bulk.

Furthermore, $\partial n / \partial x(=\partial p / \partial x)$ can be determined by solving the ambipolar diffusion equation in the neutral region $(\delta n \simeq \delta p)$, where the pair generation $\left(\alpha \varphi_{0} \exp (-\alpha x)\right)$ takes place.
Assuming that the drift term of minority carriers is negligible we can deduce the two following equations :

$\varphi_{0}\left(1-\frac{\exp (-\alpha W)}{\alpha L_{\mathrm{p}}+1}\right)+J_{\mathrm{nc}}^{*}=n_{0}\left|\mu_{\mathrm{n}}\right| \frac{V_{\mathrm{sc}}}{l}+\frac{D_{\mathrm{p}}}{L_{\mathrm{p}}} \delta n$

$\varphi_{0}\left(1-\frac{\exp (-\alpha W)}{\alpha L_{\mathrm{p}}+1}\right)+J_{\mathrm{pc}}^{*}=\frac{D_{\mathrm{p}}}{L_{\mathrm{p}}} \delta n$

$V_{\mathrm{sc}}$ is the voltage drop across the neutral region :

$$
V_{\mathrm{sc}}=U-V=U-\left(\delta V_{\mathrm{s}}+\delta U_{\mathrm{s}}\right)
$$

$U$ being the total voltage across the whole structure (Fig. 1b).

The equations (10), (15), (16) and (17) form a non linear system with $\delta n, \delta V_{\mathrm{s}}, \delta U_{\mathrm{s}}, V_{\mathrm{sc}}$ as unknown quantities.

The numerical solution of the above system (using an IBM 360 computer) allows us to determine the $(J, U)$ characteristics of the MIS structure. $J$, the total current density is given by :

$$
J=q\left(J_{\mathbf{p c}}^{*}-J_{\mathbf{n c}}^{*}\right) .
$$

Several quantities can be taken into account as parameters for the $(J, U)$ curves. The most important are : the oxide thickness $\delta$, the density $N_{\mathrm{t}}$ and the energy level $E_{\mathrm{t}}$ of the interface states.

3. Results : $(J, U)$ characteristics. - As mentioned above, the interface states can have an acceptorlike or donor-like behaviour. Furthermore, they can be connected with one, two or the three reservoirs of free carriers.

The results concerning the ideal case $\left(N_{\mathrm{t}}=0\right.$, $C_{\mathrm{p}}=C_{\mathrm{n}}=0$ ) and those concerning interface states having mainly an electrostatic action (i.e. connected with one reservoir) have been presented in detail in previous papers $[6,7,8]$. It was shown that the electrostatic action of acceptor-like interface states improves the efficiency of the MIS diode; on the contrary donor-like interface states are unfavourable. Therefore in this section we will mainly focuse our attention to the kinetic influence of interface states. The interface states can act as recombination centers if they are connected only with the valence and conduction bands of the semiconductor

$$
\left(C_{\mathrm{n}}>0, C_{\mathrm{p}}>0,1 / \tau=0\right) .
$$

They can be also connected with one (at least) permitted band of the semiconductor and the conduction band of the metal $\left(1 / \tau>0, C_{\mathrm{n}} \geqslant 0, C_{\mathrm{p}} \geqslant 0\right)$; in this case they provide an additional path for carrier transport between the metal and the semiconductor.

In the next paragraphs $(J, U)$ typical characteristics (for acceptor and donor-like states) corresponding to two thicknesses $\delta(15 \AA$ and $25 \AA)$ of the insulating 
layer will be presented and analyzed. In order to give emphasis in the kinetic properties of the surface states all the curves are computed for the maximum electron and hole capture probabilities : $\sigma_{\mathrm{n}, \mathrm{p}} \cdot N_{\mathrm{t}}=1$. Generally we have chosen for our computation a low density $\left(N_{\mathrm{t}}=10^{15} / \mathrm{m}^{2}\right)$ and a large cross-section $\left(\sigma_{\mathrm{n}, \mathrm{p}}=10^{-15} \mathrm{~m}^{2}\right)$.

Nevertheless in some interesting cases the opposite choice is made : $N_{\mathrm{t}}=10^{17} / \mathrm{m}^{2}$ and $\sigma_{\mathrm{n}, \mathrm{p}}=10^{-17} \mathrm{~m}^{2}$; a large density of states makes their electrostatic action not negligible.

In addition, in each figure a dashed curve representing the ideal case will be given for comparison.
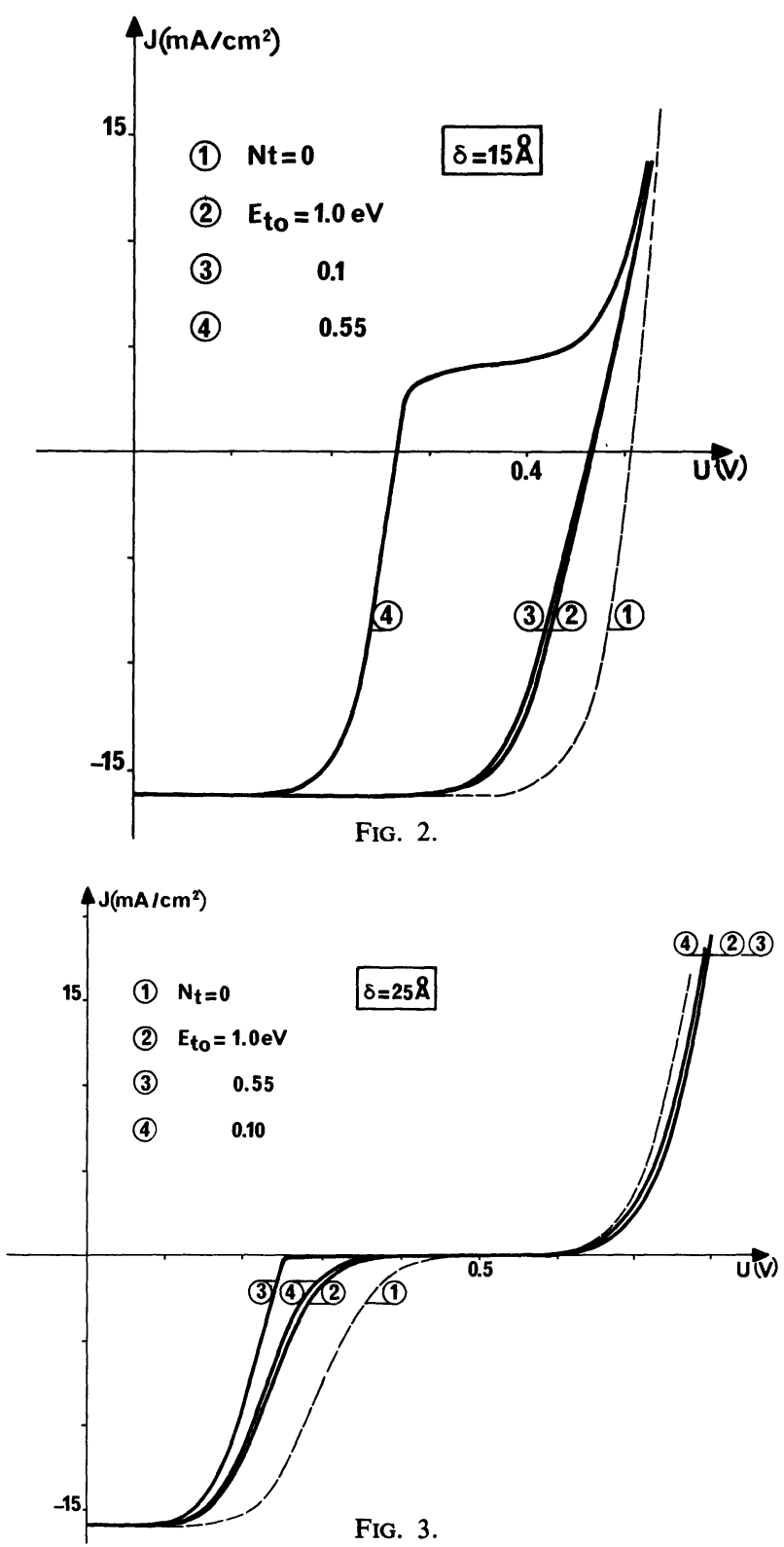

Figs. 2 and 3. - $(J, U)$ characteristics of the MIS solar cell with single energy level acceptor-like interface states, connected with the semiconductor conduction and valence bands

$$
C_{\mathrm{n}}=C_{\mathrm{p}}=5 \times 10^{-11} \mathrm{~m}^{3} \mathrm{~s}^{-1}, \quad 1 / \tau_{0}=0, \quad N_{\mathrm{t}}=10^{15} \mathrm{~m}^{-2} ;
$$

the dashed line curves correspond to the ideal $\left(N_{t}=0\right)$ MIS structure.
3.1 ACCEPTOR-LIKE INTERFACE STATES. - 3.1.1 Interface states non interacting with the metal $(1 / \tau=0)$ (see Figs. 2 and 3). - These states behave as recombination or generation centers located at the interface between the insulator and the semiconductor. They have an unfavourable influence on the working of the cell because they reduce the $V_{\text {oc }}$ voltage with respect to the ideal case ; this $V_{\text {oc }}$ decreasing is due to the recombination through the states which is important in open circuit conditions (large electrons and holes densities at the surface of the semiconductor). This effect is as much more pronounced as the states are energy located nearer to the midgap where their recombination efficiency is enhanced. On the contrary, the short-circuit current is not affected by their action : the absence of a suppression current effect is to be attributed to a weak recombination current between an almost filled (with holes) valence band and an almost empty (of electrons) conduction band.

It is worth to comment the different origins of the plateau appearing for the two different thicknesses.

The plateau $(J \simeq 0)$ corresponding to $\delta=25 \AA$ is due to the large tunneling resistance for this thickness ; the current is growing again for larger voltages when the interface band bending provokes an increasing injection of majority carriers.

For thinner insulating layers (for ex. $\delta=15 \AA$ ) a plateau $(J>0)$ is appearing for states located near the midgap and for comparable values of the voltage.

For these thicknesses the tunnel effect cannot be incriminated : in fact the shape of the $(J, U)$ characteristics is controlled by the interface states for $U<0.45 \mathrm{~V}$. The forward current being opposed to the photocurrent is essentially the recombination current $J_{\mathbf{R}}$ plotted in figure 4 . This current exhibits a

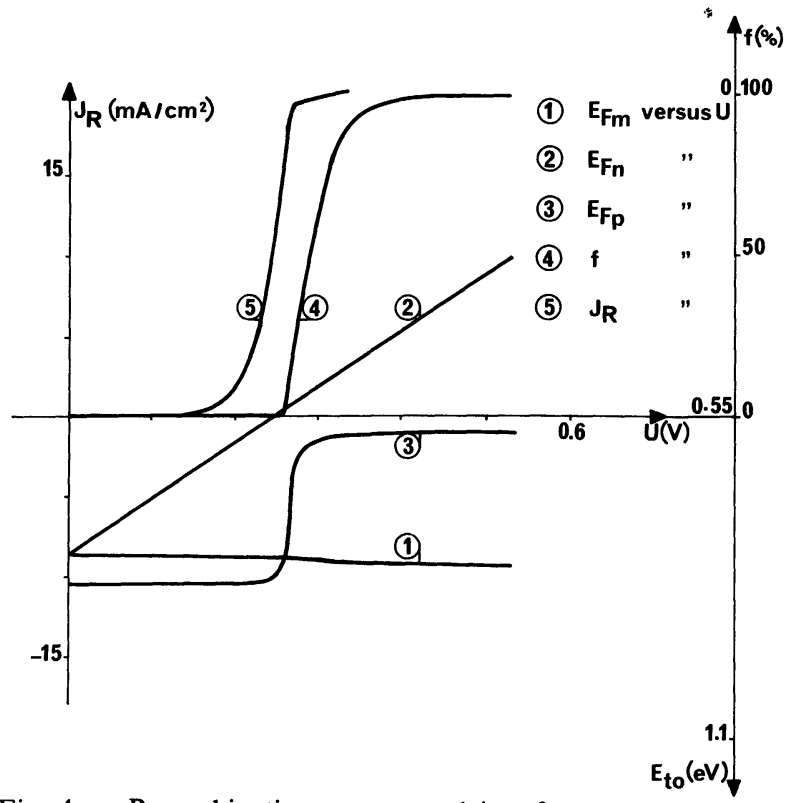

Fig. 4. - Recombination current and interface states occupancy versus the external MIS diode voltage $U$, corresponding to the parameters $E_{\mathrm{t}_{0}}=0.55 \mathrm{eV}$ and $\delta=15 \AA$ (Fig. 2). In addition, the energy positions of $E_{\mathrm{Fm}}, E_{\mathrm{Fn}}, E_{\mathrm{Fp}}$ are also plotted versus the external voltage $U$. 
sharp increase around $V=0.25 \mathrm{~V}$, which is due to the improved recombination efficiency resulting from the increase of $n_{\mathrm{s}}$ in forward bias. The sharp increase of $J_{R}$ is followed by a plateau because the states are filled with electrons. The sharp variation of $E_{\mathrm{Fp}}$ (Fig. 4) is correlated with an increase of $J_{\mathrm{R}}$ and corresponds to a strong decrease of $p_{\mathrm{s}}$ (recombination enhancement). Besides, we observe that the occupation rate of. the interface states is equal to 0.5 when the states energy level $E_{\mathrm{t}}$ is equidistant from the imrefs $E_{\mathrm{Fn}}$ and $E_{\mathrm{Fp}}$; we deduce that when the cell works (far from thermodynamic equilibrium) the occupancy of interface states is not governed by a Fermi-like function.
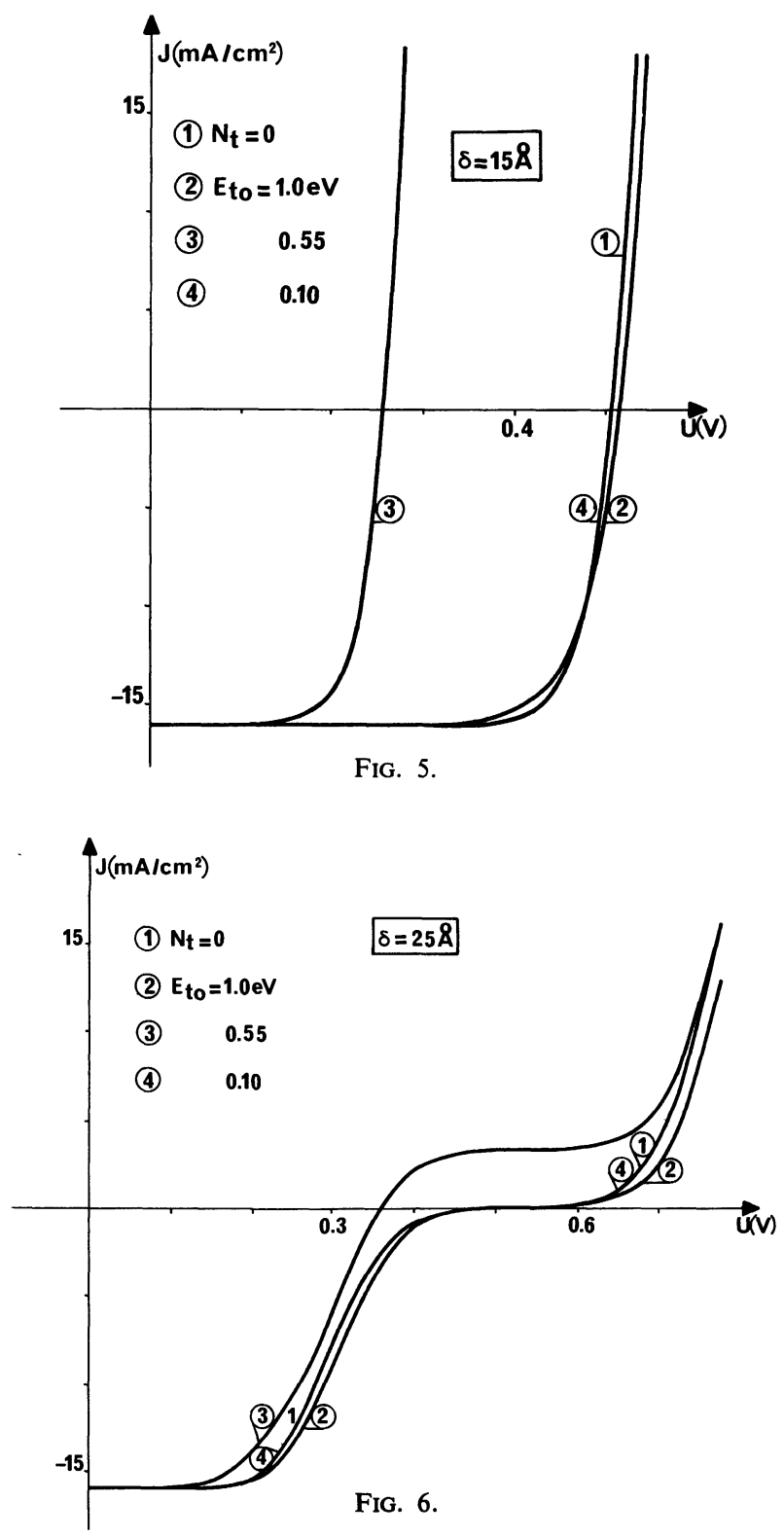

Figs. 5 and 6. - $(J, U)$ characteristics of the MIS structure with acceptor-like interface states interacting with the metal and the semiconductor conduction band

$$
\begin{gathered}
C_{\mathrm{n}}=5 \times 10^{-11} \mathrm{~m}^{3} \mathrm{~s}^{-1}, \quad C_{\mathrm{p}}=0, \quad 1 / \tau_{0}=10^{13} \mathrm{~s}^{-1}, \\
N_{\mathrm{t}}=10^{15} \mathrm{~m}^{-2} .
\end{gathered}
$$

3.1.2 Interface states connected with the metal $(1 / \tau>0)$. - We examine the three possible cases :

a) Surface states communicating with the metal and the conduction band of the semiconductor (Figs. 5, 6).

In this case when the surface states are located near the midgap we observe as in the previous one (3.1.1) a decreasing of $V_{\text {oc }}$ due to the additional flux of majority carriers through the surface states $\left(J_{\mathrm{nt}}=j_{\mathrm{mt}}\right.$ when the valence band is isolated). On the contrary, the interface states the energy level of which is located near the permitted energy bands, do not influence the
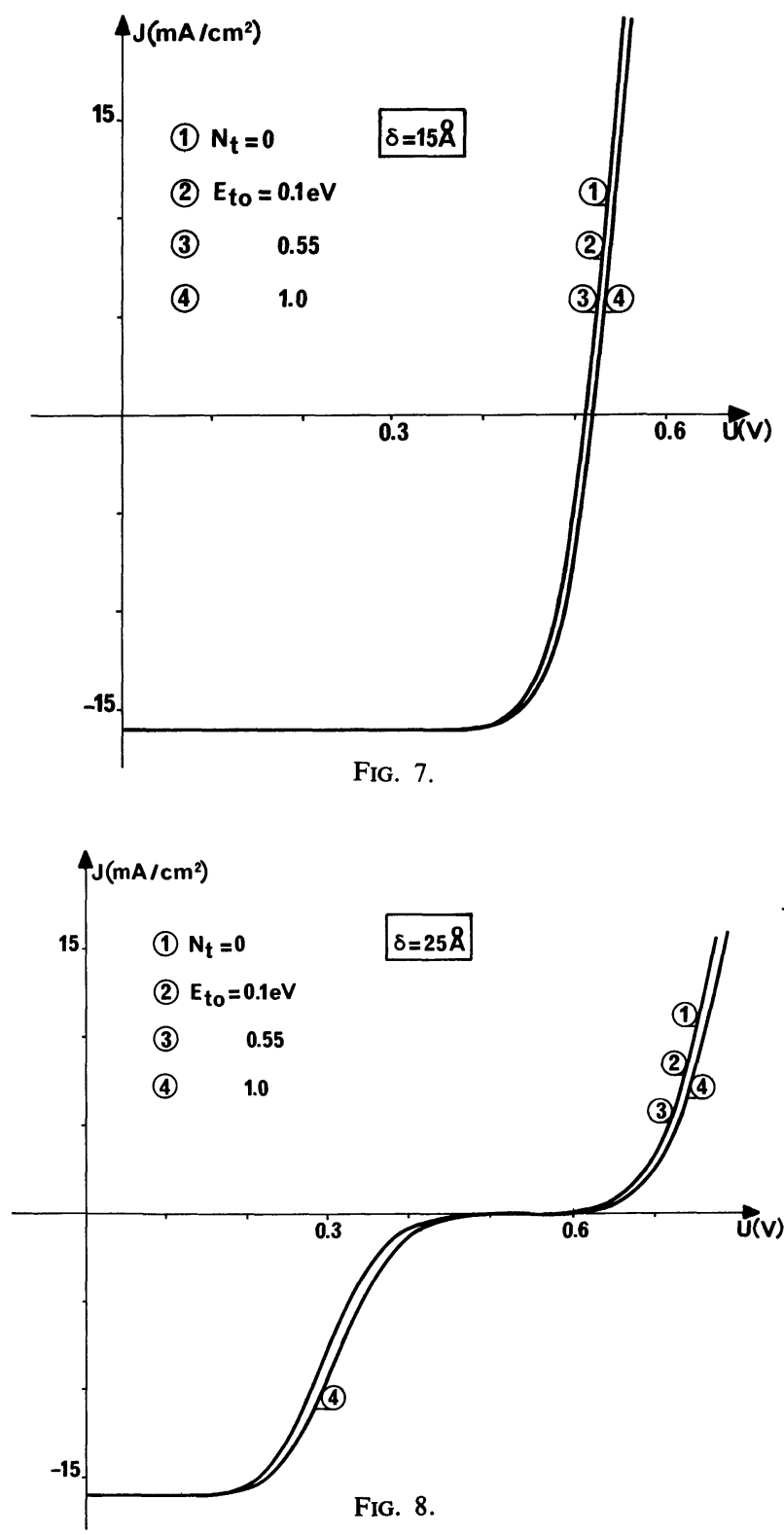

Figs. 7 and 8. - $(J, U)$ characteristics of the MIS solar cell with acceptor-like interface states interacting with the metal and the semiconductor valence band

$$
\begin{gathered}
C_{\mathrm{p}}=5 \times 10^{-11} \mathrm{~m}^{3} \mathrm{~s}^{-1}, C_{\mathrm{n}}=0, \quad 1 / \tau_{0}=10^{13} \mathrm{~s}^{-1}, \\
N_{\mathrm{t}}=10^{15} \mathrm{~m}^{-2} .
\end{gathered}
$$


efficiency of the cell; they are inefficient majority carriers path. Indeed, if the surface states are located near the conduction band they are in equilibrium with semiconductor electrons; if they are located near the valence band they are in equilibrium with the metal, because they do not communicate with the valence band (hypothesis) and they are too far from the conduction band. In addition, current is not suppressed as it can be expected (no recombination and no lowering of the barrier). Finally, in a voltage range corresponding to a weak band bending $J_{\mathrm{nt}}$ becomes notable and in certain cases $\left(\delta=25 \AA, E_{\mathrm{t}_{\mathrm{o}}}=0.55 \mathrm{eV}\right.$, see Fig. 6) a current plateau is appearing. According to equations (3) and (8) the value of the current plateau
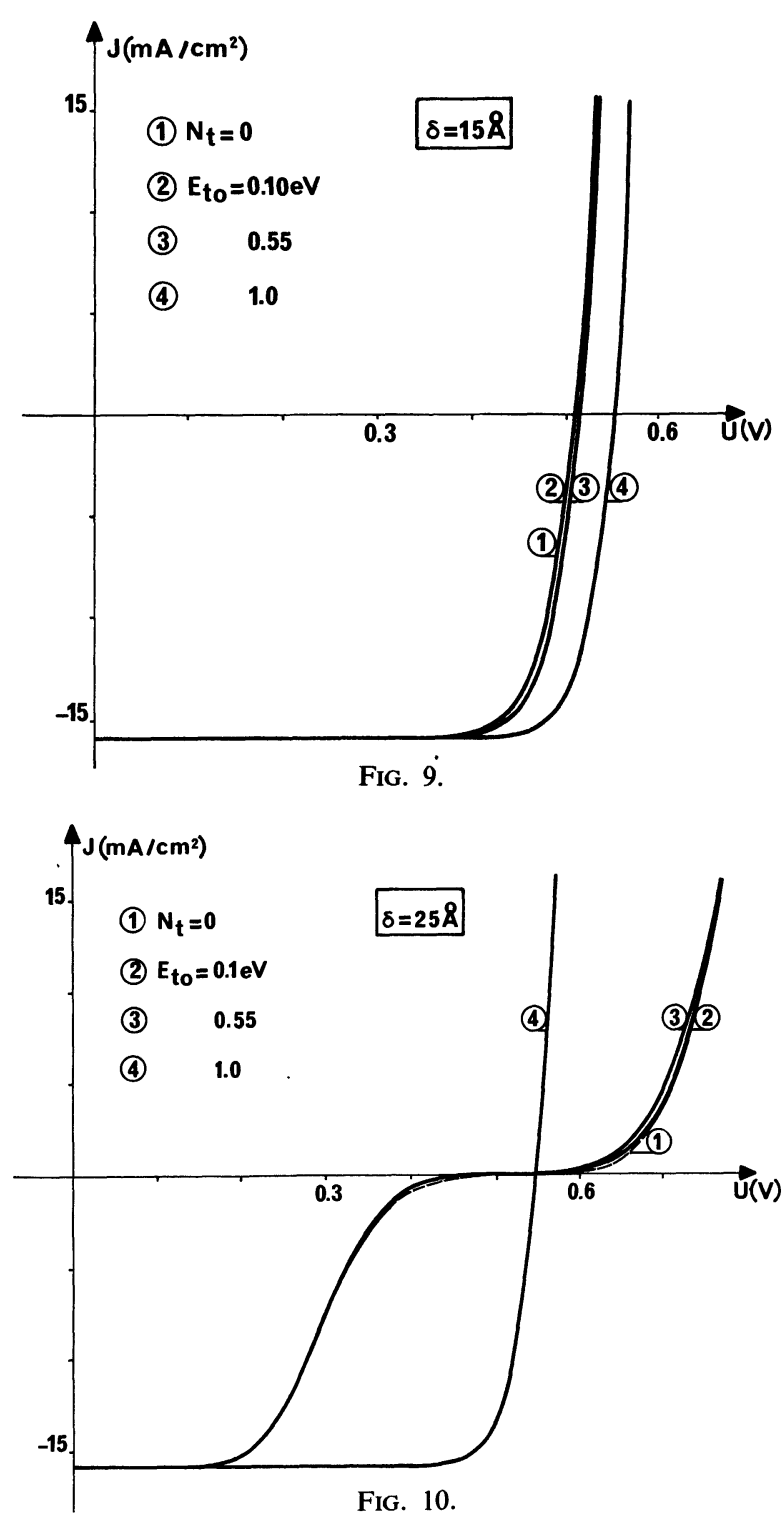

Figs. 9 and 10. $-(J, U)$ characteristics of the MIS solar cell with acceptor-like interface states connected with the metal and the semiconductor valence band, showing a notable improvement of the photovoltaic yield of the structure

$$
\begin{gathered}
C_{\mathrm{p}}=5 \times 10^{-13} \mathrm{~m}^{3} \mathrm{~s}^{-1}, \quad C_{\mathrm{n}}=0, \quad 1 / \tau_{0}=10^{13} \mathrm{~s}^{-1}, \\
N_{\mathrm{t}}=10^{17} \mathrm{~m}^{-2} .
\end{gathered}
$$

is $q N_{\mathrm{t}} / \tau$ (the states are filled with electrons that is $f=1 ; f_{\mathrm{m}}=0, E_{\mathrm{t}}$ being above $\left.E_{\mathrm{Fm}}\right)$.

b) Interface states communicating with the metal and the valence band of the semiconductor (Figs. 7, 8,9 and 10).

The introduction of interface states facilitating the communication between the metal and the semiconductor valence band does not worsen the yield of the cell ; furthermore if their density is on the order of $10^{17} \mathrm{~m}^{-2}$ they improve notably the working of the structure (Figs. 9 and 10); the closer to the valence band is the energy level of the states, the better is the $(J, U)$ curve of the MIS diode.
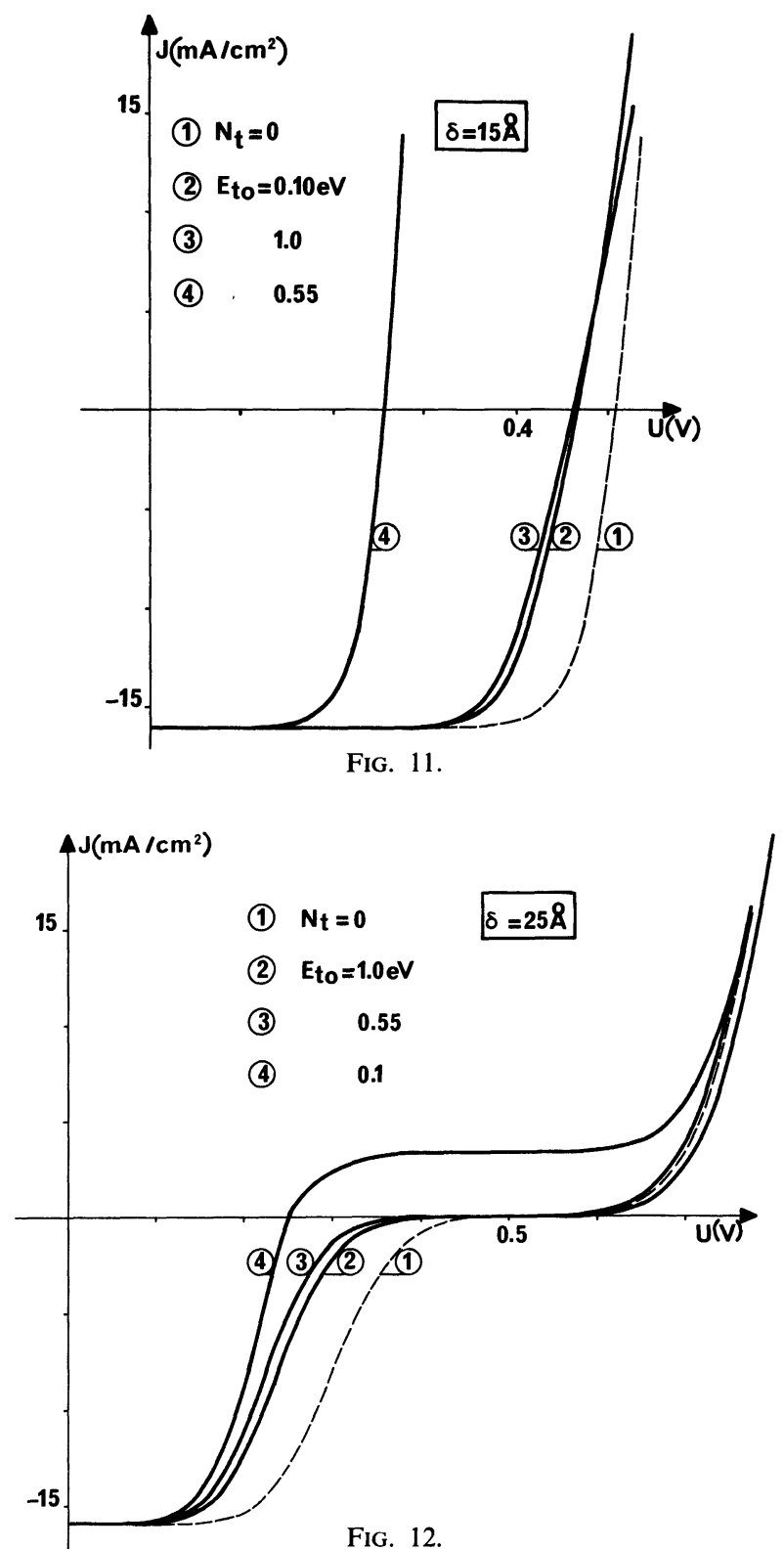

Figs. 11 and 12. - $(J, U)$ characteristics of the MIS solar cell with acceptor-like interface states interacting with the three reservoirs of free carriers (general case)

$$
\begin{gathered}
C_{\mathrm{n}}=C_{\mathrm{p}}=5 \times 10^{-11} \mathrm{~m}^{3} \mathrm{~s}^{-1}, 1 / \tau_{0}=10^{13} \mathrm{~s}^{-1}, \\
N_{\mathrm{t}}=10^{15} \mathrm{~m}^{-2} .
\end{gathered}
$$


Indeed, the above improvement of the structure is due to both electrostatic and kinetic action of the states : on the one hand the charge of the states leads to an increasing of the surface barrier while, on the other hand, the communication between the metal and the valence band tends to maintain the photocurrent.

c) General case : interface states connected with the three reservoirs (Figs. 11, 12, 13).

Actually the interface states are connected with the permitted bands of the semiconductor and the conduction band of the metal. Therefore, in this general case, according to the values of the kinetic parameters $\left(C_{\mathrm{p}}, C_{\mathrm{n}}, 1 / \tau\right)$, the density and the energy level of states, we can approach all the previously treated cases. Consequently, if the recombination and the communication between the semiconductor conduction band and the metal prevail, the working of the MIS cell is bad (Figs. 11 and 12 ; to be compared with Figs. 5 and 6). On the contrary, we observe an improvement of the shape of $(J, U)$ characteristics when the communication between the valence band and the metal is easier (Fig. 13; to be compared with Figs. 9 and 10).

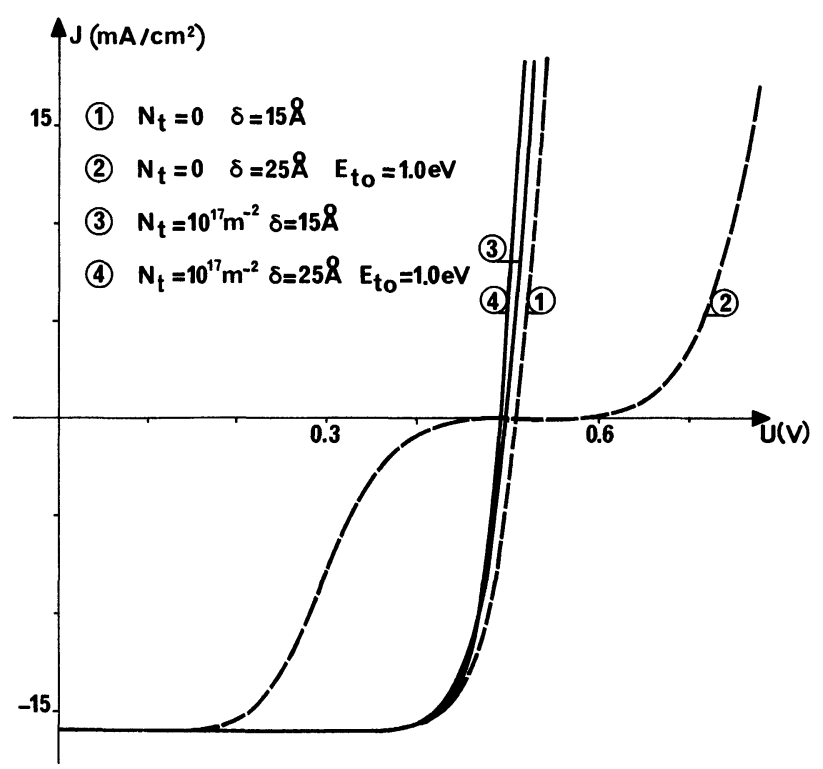

Fig. 13. - $(J, U)$ characteristics of the MIS structure with acceptorlike interface states interacting with the metal and the semiconductor conduction and valence energy bands (general case)

$$
\begin{gathered}
C_{\mathrm{n}}=C_{\mathrm{p}}=5 \times 10^{-13} \mathrm{~m}^{3} \mathrm{~s}^{-1}, \quad 1 / \tau_{\mathrm{o}}=10^{13} \mathrm{~s}^{-1}, \\
N_{\mathrm{t}}=10^{17} \mathrm{~m}^{-2} .
\end{gathered}
$$

3.2 DONOR-LIKE INTERFACE STATES (Figs. 14 and 15). - Donor-like interface states of a low density $\left(N_{\mathrm{t}}=10^{15} \mathrm{~m}^{-2}\right)$ lead to the same results as in the acceptor-like case; in the two cases the action of the states is only kinetic. For a large density $\left(N_{\mathrm{t}}=10^{17} \mathrm{~m}^{-2}\right)$ the electrostatic charge of states, when they are not completely occupied, provokes a lowering of the surface barrier and therefore they deteriorate the yield of the cell.

So we can observe not only a low $V_{\text {oc }}$ but also an important current suppression effect which does not appear when only acceptor-like states are present. As in the previous section 3.1 , all the interesting cases have been studied; we present here as a typical example (Figs. 14, 15) two sets of $(J, U)$ characteristics corresponding to states not communicating with the metal.

The lowering of the surface barrier results in :

a) A notable current suppression effect due to a large recombination current.

b) A steep increase of the reverse current is observed, due to the approaching of the metal Fermi level toward the conduction band, which results from the accumulation of positive charges in the interface (free and trapped holes) [19].

Besides it is worth to notice that the action of donorlike interface states may invert the rectifying properties of the diodes (see Figs. 14, 15).
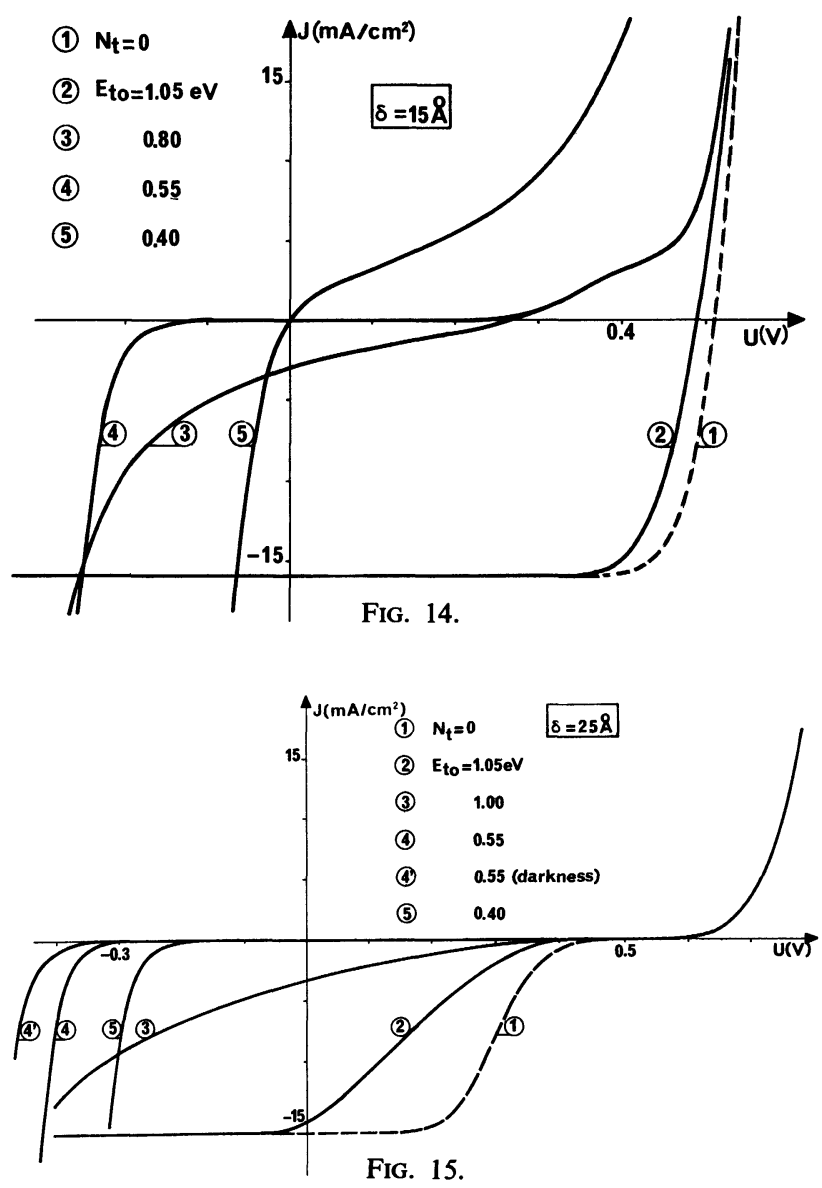

Figs. 14 and 15. - $(J, U)$ characteristics of the MIS structure with donor-like interface states interacting with the semiconductor conduction and valence bands

$$
C_{\mathrm{n}}=C_{\mathrm{p}}=5 \times 10^{-13} \mathrm{~m}^{3} \mathrm{~s}^{-1}, 1 / \tau_{0}=0, N_{\mathrm{t}}=10^{17} \mathrm{~m}^{-2} .
$$


4. Conclusion. - Our complete and rigorous theoretical analysis of the photovoltaic working of the MIS tunnel diode, taking into account both kinetic and electrostatic influence of the interface states, lead us to the main following conclusions :

- Donor-like interface states located around the midgap are unfavourable to the photovoltaic working of the cell peculiarly when their density exceeds $10^{16} / \mathrm{m}^{2}$.

- On the contrary a large density $\left(N_{\mathrm{t}}>10^{16} / \mathrm{m}^{2}\right)$ of acceptor-like interface states located in energy near the valence band results in an excellent efficiency of the cell for a large range of insulator thicknesses $(10 \AA<\delta<30 \AA)$; then this parameter becomes less critical which is quite interesting for technological applications.

- Finally it is shown that it is mainly the unfavourable electrostatic action of interface states and not the recombination through them which originates current suppression effect; on the other hand recombination effects can lower the open circuit voltage.

Appendix. - The expressions of the fluxes $J_{\mathrm{nc}}, J_{\mathrm{pc}}, j_{\mathrm{m}}$ can be very simply deduced by means of our chemical-thermodynamical formalism $[16,17,18]$.

a) The interaction between the metal and the semiconductor conduction band is described by the following chemical-like reaction :

$$
e_{\mathrm{m}} \stackrel{w_{1}}{\rightleftarrows} e
$$

$e_{\mathrm{m}}$ denotes the metal free electrons,

$e$ represents the free electrons at the semiconductor surface,

$w_{1}$ is the reaction velocity.

In steady state conditions we can write :

$$
J_{\mathrm{nc}}=w_{1}=\vec{k}_{1} f_{\mathrm{m}}-\overleftarrow{k}_{1} n_{\mathrm{s}}\left(1-f_{\mathrm{m}}\right)
$$

where $\vec{k}_{1}, \overleftarrow{k_{1}}$ are the kinetic coefficients of the chemical reaction.

Under thermal equilibrium conditions, $w_{1}=0$ and we deduce from equation (A.2) :

$$
\vec{k}_{1}=\overleftarrow{k_{1}} \frac{n_{\mathrm{s}_{0}}}{f_{\mathrm{m}_{0}}}
$$

$n_{\mathrm{s}}, f_{\mathrm{m}_{0}}$ are the equilibrium values of $n_{\mathrm{s}}, f_{\mathrm{m}}$. With the basic assumption that $E_{\mathrm{c}}-E_{\mathrm{Fm}} \gg k T$ and taking into account the expressions of $f_{\mathrm{m}}, n_{\mathrm{s}}, \vec{k}_{1}$ the equation (A.2) becomes :

$$
\begin{aligned}
J_{\mathrm{nc}}=\overleftarrow{k}_{1} n_{0} \exp \left(-\frac{q U_{\mathrm{s}}}{k T}\right) \exp \left(-\frac{\varphi_{\mathrm{ms}}}{k T}\right) \times \\
\times\left[1-\frac{n}{n_{0}} \exp \left(\frac{q V}{k T}\right)\right] .
\end{aligned}
$$

Considering that the carriers cross the insulating layer by tunnel effect, we can determine the kinetic coefficient $\overleftarrow{k}_{1}$ and therefore (A.4) becomes :

$$
\begin{aligned}
J_{\mathrm{nc}}=\mathrm{e}^{-\chi^{1 / 2} \delta} V_{\mathrm{cn}} \cdot n_{0} \exp \left(-\frac{q U_{\mathrm{s}}}{k T}\right) \exp \left(-\frac{\varphi_{\mathrm{ms}}}{k T}\right) \times \\
\times \\
{\left[1-\frac{n}{n_{0}} \exp \left(\frac{q V}{k T}\right)\right] . }
\end{aligned}
$$

b)In a similar manner we can determine the expression of the flux $J_{\mathrm{pc}}$ by means of the chemical-like reaction :

$$
e_{\mathrm{m}}+G^{+} \rightleftarrows G
$$

where $\mathrm{G}^{+}$is the density of holes at the semiconductor surface (that is the density of the ionized atoms at the semiconductor surface).

c) Using the above mentionned formalism we consider now the reaction :

$$
e_{\mathrm{m}}+I \stackrel{w_{2}}{\rightleftarrows} I^{-}
$$

where $I$ represents the impurities located at the insulator-semiconductor interface ; in case of acceptorlike (donor-like) impurities, $I$ is neutral (positively charged).

The flux $j_{\mathrm{mt}}$ is then given by :

$j_{\mathrm{mt}}=w_{2}=\vec{k}_{2} f_{\mathrm{m}} N_{\mathrm{t}}(1-f)-\overleftarrow{k_{2}}\left(1-f_{\mathrm{m}}\right) N_{\mathrm{t}} f$.

In thermal equilibrium conditions $j_{\mathrm{mt}}=\mathbf{0}$ and $f_{\mathrm{m}_{0}}=f_{0}$; it follows from the above equation that $\vec{k}_{2}=k_{2}$ and

$$
j_{\mathrm{mt}}=\vec{k}_{2} N_{\mathrm{t}}\left(f_{\mathrm{m}}-f\right) .
$$

According to [15] the kinetic coefficient $\vec{k}_{2}$ is written :

$$
\vec{k}_{2}=\frac{1}{\tau}=\frac{1}{\tau_{0} \mathrm{e}^{x^{1 / 2} \delta}} .
$$

Finally, from (A.6), (A.7) :

$$
j_{\mathrm{mt}}=\frac{N_{\mathrm{t}}}{\tau}\left(f_{\mathrm{m}}-f\right) \text {. }
$$

\section{Notation and used numerical values}

$C_{\mathrm{n}, \mathrm{p}} \quad$ electron and hole capture coefficients; $C_{\mathrm{n}}=C_{\mathrm{p}}=5 . \times 10^{-11}$

(or $\left.5 . \times 10^{-13}\right) \mathrm{m}^{3} \mathrm{~s}^{-1}$.

$C_{\mathrm{n}, \mathrm{p}}=\sigma_{\mathrm{n}, \mathrm{p}} \cdot \theta_{\mathrm{n}, \mathrm{p}} ; \sigma_{\mathrm{n}, \mathrm{p}}:$ capture cross sections of electrons and holes; $\theta_{\mathrm{n}, \mathrm{p}}$ : thermal velocities of carriers $\sigma_{\mathrm{n}}=\sigma_{\mathrm{p}}=10^{-15}$ (or $\left.10^{-17}\right) \mathrm{m}^{2} ; \theta_{\mathrm{n}}=\theta_{\mathrm{p}}=5 . \times 10^{4} \mathrm{~ms}^{-1}$.

$D_{\mathrm{n}}, D_{\mathrm{p}} \quad$ electron and hole diffusion coefficients;

$$
\begin{aligned}
& D_{\mathrm{n}}=3.25 \times 10^{-3} \mathrm{~m}^{2} \mathrm{~s}^{-1} ; \\
& D_{\mathrm{p}}=1.25 \times 10^{-3} \mathrm{~m}^{2} \mathrm{~s}^{-1} .
\end{aligned}
$$


$E \quad$ electric field in the semiconductor.

$E_{\mathrm{g}} \quad$ energy gap of the semiconductor.

$E_{\mathrm{t}} \quad$ energy level of interface states which is referred to the conduction band (parameters $E_{\mathrm{t}_{\mathrm{o}}}=E_{\mathrm{c}}-E_{\mathrm{t}}$ ).

$E_{\mathrm{c}}, E_{\mathrm{v}} \quad$ semiconductor band edges at the surface.

$E_{\mathrm{Fm}}$ metal Fermi level.

$E_{\mathrm{Fn}}, E_{\mathrm{Fp}}$ electron and hole imrefs in the semiconductor.

$f \quad$ occupancy of the interface states (energy $E_{\mathrm{t}}$ ).

$f_{\mathrm{m}} \quad$ metal Fermi function.

$J \quad$ total current density of the MIS structure.

$k \quad$ Boltzmann's constant ;

$$
k=1.38 \times 10^{-23} \mathrm{~J} / \mathrm{K} .
$$

$l \quad$ length of the structure; $l=0.5 \mathrm{~mm}$.

$L_{\mathrm{p}} \quad$ hole diffusion length; $L_{\mathrm{p}}=50 \mu \mathrm{m}$.

$N_{\text {D }} \quad$ semiconductor doping; $N_{\mathrm{D}}=10^{22} \mathrm{~m}^{-3}$.

$N_{\mathrm{t}} \quad$ density of single level interface states; $N_{\mathrm{t}}=10^{15}$ (or $\left.10^{17}\right) \mathrm{m}^{-2}$.

$N_{\mathrm{c}}, N_{\mathrm{v}} \quad$ effective density of states in the conduction and valence band of the semiconductor. $n_{\mathrm{i}} \quad$ intrinsic carrier density; $n_{\mathrm{i}}=10^{16} \mathrm{~m}^{-3}$. $n_{\mathrm{s}}, p_{\mathrm{s}} \quad$ electron and hole densities at the semiconductor surface.

$n_{0}, p_{0} \quad$ electron and hole bulk densities in equilibrium.

$n, p \quad$ electron and hole densities at the neutral bulk boundary out of equilibrium (Fig. 1a); $\delta n=n-n_{0}=\delta p=p-p_{0}$.

$q \quad$ electron charge $q=1.6 \times 10^{-19} \mathrm{C}$.

$T \quad$ absolute temperature $; k T=4 . \times 10^{-21} \mathrm{~J}$.

$U$ total voltage across the MIS structure.

$U_{\mathrm{s}_{0}}, U_{\mathrm{s}} \quad$ equilibrium (non equilibrium) voltage drop across the insulating layer.
$V_{\mathrm{s}_{0}}, V_{\mathrm{s}}$ equilibrium (non equilibrium) surface potential of the semiconductor.

$V \quad$ voltage drop across the junction ;

$$
V=V_{\mathrm{s}}+U_{\mathrm{s}}-U_{\mathrm{s}_{0}}-V_{\mathrm{s}_{0}} \text {. }
$$

$V_{\mathrm{cn}}, V_{\mathrm{cp}}$ collection velocities of electrons and holes at the insulator-semiconductor interface;

$$
V_{\mathrm{cn}}=V_{\mathrm{cp}}=5 . \times 10^{4} \mathrm{~ms}^{-1} \text {. }
$$

$w \quad$ depletion layer width.

$\alpha \quad$ absorption coefficient of light ;

$\delta \quad$ insulator thickness.

$$
1 / \alpha=\mathrm{L}_{\mathrm{p}}=50 \mu \mathrm{m} \text {. }
$$

$\varepsilon_{0}, \varepsilon_{\mathrm{i}}, \varepsilon_{\mathrm{s}} \quad$ permittivities of the free space, the insulator and the semiconductor respectively;

$$
\begin{gathered}
\varepsilon_{0}=8.85 \times 10^{-12} \mathrm{Fm}^{-1} ; \\
\varepsilon_{\mathrm{i}}=4 \times \varepsilon_{0} ; \varepsilon_{\mathrm{s}}=12 \times \varepsilon_{0} .
\end{gathered}
$$

$\mu_{\mathrm{n}}, \mu_{\mathrm{p}} \quad$ electron and hole mobilities;

$$
\begin{aligned}
& \mu_{\mathrm{n}}=0.13 \mathrm{~m}^{2} \mathrm{~s}^{-1} \text { (volt) }^{-1} \\
& \mu_{\mathrm{p}}=0.05 \mathrm{~m}^{2} \mathrm{~s}^{-1} \text { (volt) }^{-1} .
\end{aligned}
$$

$\tau_{0} \quad$ tunnelling constant for $\delta$ tending to zero ; $\tau_{0}=10^{-13} \mathrm{~s}$; in the presence of the insulator this constant is written :

$\tau=\tau_{0} \mathrm{e}^{\chi^{1 / 2}}$ with $\chi=\chi_{\mathrm{n}}=\chi_{\mathrm{p}} ; \chi_{\mathrm{n}, \mathrm{p}}:$ barrier heights of the insulator layer for semiconductor electrons and holes ; $\chi$ is expressed in $\mathrm{eV}, \delta$ in $\AA$.

$\varphi_{\mathrm{ms}}=\varphi_{\mathrm{m}}-\left(\chi+\frac{E_{\mathrm{g}}}{2}+k T \ln \frac{n_{\mathrm{i}}}{n_{0}}\right) ;$ difference between workfunctions of the metal and the semiconductor; $\varphi_{\mathrm{ms}}=0.6 \mathrm{eV}$.

$\varphi_{0} \quad$ flux of incident light;

$$
\varphi_{0}=2 . \times 10^{21} \mathrm{~m}^{-2} \mathrm{~s}^{-1} \simeq 1 \mathrm{AM} 1
$$

at the insulator semiconductor interface. barrier height of the insulator layer for metal electrons.

\section{References}

[1] Stirn, R. J. and Yeh, Y. C. M., Appl. Phys. Lett. 27 (1975) 95.

[2] Lillington, D. R. and Townsend, W. G., Appl. Phys. Lett. 28 (1976) 97.

[3] Ponpon, J. P. and Siffert, P., J. Appl. Phys. 47 (1976) 3248.

[4] Fonash, J., J. Appl. Phys. 46 (1975) 1286.

[5] Singh, R. and Shewchun, J., Appl. Phys. Lett. 28 (1976) 512.

[6] Viktorovitch, P., Kamarinos, G., Even, P., C.R. Hebd. Séan. Acad. Sci. 283B (1976) 119, see also :

Viktorovitch, P., Kamarinos, G., Even, P., Com. at 12th IEEE Photovoltaic Specialists Conference Bâton Rouge, USA, nov. 15-18 (1976) Proceed. p. 870.

[7] Viktorovitch, P., Kamarinos, G., Even, P. and Fabre, E., Phys. Status Solidi (a) 48 (1978) 137.

[8] Pananakakis, G., Viktorovitch, P. and Ponpon, J. P., Revue Phys. Appl. 13 (1978) 449.

[9] KAR, S. and DaHLKe, W. E., Solid State Electr. 15221 (1972).

[10] Hirose, M., Hiraki, S., Nakashita, T. and Osaka, Y., J. J. Appl. Phys. 14 (1975) 999.

[11] Card, H. C. and Yang, E. S., Appl. Phys. Lett., 29 (1976) 51.
[12] Viktorovitch, P., Kamarinos, G., J. Appl. Phys. 48 (1977) 3060.

[13] Viktorovitch, P., Pananakakis, G., Kamarivos, G., Basset, R., Proceedings of the Photovoltaic Solar Energy Conf., Luxembourg, 937 (1977), see also :

Proceedings IEDM, Washington, USA, 62 (1977).

[14] Many, A., Goldstein, Y., Grover, N. B., Semiconductor surfaces (North Holland Ptb., London) 1965, 194.

[15] Freeman, L. B., Dahlke, W. E., Solid State Electron. 13 (1970) 1483

[16] Viktorovitch, P., Kamarinos, G., C.R. Hebd. Séan. Acad. Sci. 277B (1973) 305.

[17] Viktorovitch, P., Kamarinos, G., J. Chem. Phys. 62 (1975) 1532.

[18] Viktorovitch, P., Kamarinos, G., Com. at « Conference on metal-semiconductor contact ", Manchester, 3-5 April (1974) Inst. of Phys. 22, 36 (1975).

[19] Green, M. A., Shewchun, J., Solid State Electron. 17 (1974) 349 . 